\title{
Modifiye Hummers Yöntemi ile Elde Edilen Grafen Oksit Sentezleri İçin: Kısım3, Fourier Dönüşümlü Kızılötesi Spektroskopisi Analizi
}

\author{
Ömer Laçin ${ }^{*}$, Bünyamin Dönmez ${ }^{1}$ \\ ${ }^{1^{*}}$ Atatürk Üniversitesi, Mühendislik Fafültesi, Kimya Mühendisliği Bölümü, Erzurum, Türkiye (ORCID ID 0000-0002-5276-3056), olacin@atauni.edu.tr \\ ${ }^{1}$ Atatürk Üniversitesi, Mühendislik Fafültesi, Kimya Mühendisliği Bölümü, Erzurum, Türkiye (ORCID ID 0000-0002-7680-0755), bdonmez@atauni.edu.tr
}

(1st International Conference on Applied Engineering and Natural Sciences ICAENS 2021, November 1-3, 2021)

(DOI: 10.31590/ejosat.1012387)

ATIF/REFERENCE: Laçin, O. \& Dönmez, B. (2021). Modifiye Hummers Yöntemi ile Elde Edilen Grafen Oksit Sentezleri İçin: Kısım 1, Fourier Dönüşümlü Kızılötesi Spektroskopisi Analizi. Avrupa Bilim ve Teknoloji Dergisi, (28), 985-989.

$\ddot{O} \mathbf{z}$

Bu çalışmada, Fourier Dönüşümlü Kızılötesi Spektroskopisi analizi ile değişen sodyum nitrat konsantrasyonlarıyla elde edilen sentezler sonucunda grafen okside dönüşümü ve yapısal özelliklerinin değişimi incelenmiş̧ir. Grafit spektrumunda, herhangi bir fonksiyonel grupla ilgili anlamlı pikler gözlenmemiş̧tir. Kimyasal oksidasyondan sonra spektrumlardan grafitin yapısal değişime uğradığı ve oksijen içeren fonksiyonel gruplara atfedilen yeni bantlar ortaya çıktı̆̆ı görülmüştür. Grafen oksit spektrumlarında mutlaka görülmesi gereken $1723 \mathrm{~cm}^{-1}$ ve $1619 \mathrm{~cm}^{-1}$ bantları sırasıyla $\sim 1717 \mathrm{~cm}^{-1}$ ve $\sim 1615 \mathrm{~cm}^{-1}$ ortaya çımıştır. Bu analizden elde edilen sonuçların, X ışını fotoelektron spektroskopisi analizindeki sonuçlarla karşılaştırıldığında uyum içerisinde olduğu gözlenmiştir. Bütün sonuçlar 1şı̆̆ında, bu şartlarda elde edilen sentezlerin, farklı özelliklere sahip grafen oksit örnekleri oldukları ve literatür ile uyum içerisinde oldukları söylenebilir.

Anahtar Kelimeler: Grafit, Grafen oksit, Hummers Yöntemi, Nanomalzeme, Fourier Dönüşümlü Kızılötesi Spektroskopi

\section{For Graphene Oxide Synthesis Obtained by Modified Hummers Method: Part 3, Fourier Transform Infrared Spectroscopy Analysis}

\begin{abstract}
In this study, the conversion of graphene to oxide and the change of its structural properties as a result of syntheses obtained with varying sodium nitrate concentrations by Fourier Transform Infrared Spectroscopy analysis were investigated. No significant peaks related to any functional group were observed in the graphite spectrum. In the spectra after chemical oxidation, it was observed that the graphite undergoes a structural changes and new bands appear in which oxygen-containing functional groups are seen. The $1723 \mathrm{~cm}-1$ and 1619 cm-1 bands, which are a must-see in the graphene oxide spectra, appeared $\sim 1717 \mathrm{~cm}-1$ and $\sim 1615 \mathrm{~cm}-1$, respectively. It was observed that the results obtained from this analysis were in good agreement with the results from the X-ray photoelectron spectroscopy analysis. In the light of all the results, it can be said that the syntheses obtained under these conditions are graphene oxide samples with different properties and are in agreement with the literature.
\end{abstract}

Keywords: Graphite, Graphene oxide, Hummers Method, Nanomaterial, Fourier Transform Infrared Spectroscopy 


\section{Giriş}

Bir karbon allotropu olan grafit, altıgen şekilli düzleminde bulunan karbon atomlarının birbirine güçlü kovalent bağlarla ve düzlemler arasının ise zayıf Van Der Walls bağlarıyla bağlanmasıyla oluşan üç boyutlu bir kristaldir. Van Der Walls bağlarının zayıf olması tabakaların birbirlerinden ayrılabilmesine neden olur. Grafit, düşük maliyetli, kolay elde edilebilir, grafen oksit ve onun türevlerinden oluşan kompozit malzemelere kolaylıkla dönüşebilmesinden dolayı son yıllarda çok büyük bir ilgi görmektedir [1-2].

2 boyutlu bir malzeme olan Grafen Oksit (GO) ise, oksijen içeren fonksiyonel grupların olduğu karbon esaslı bir malzemedir. Grafitin oksidasyonundan sonra çok sayıdaki tabakalar kolayca ayrılabildiğinden dolayı grafen oksite dönüşüm de kolaydır. Ayrıca bu yöntemle elde edilen GO'nun değişebilen, yapısal, elektronik ve optik özellikleri, hidrofilik olması ve suda çok iyi disperse olabilmesi nedeniyle, savunma sanayi, enerji, biyokimya, kaplama gibi bir çok teknolojide geniş bir uygulama alanı bulmaktadır. Sentez aşamalarında mevcut ve oluşan tehlikeli kimyasallardan dolayı, bunları indirgeyebilmek için son yıllarda grafitten grafen oksit eldesi üzerine oldukça fazla çalışma yapılmaktadır [3-8]. Ayrica bu durumdan dolay1, sentezlenen her GO'nun literatüre önemli bir katkı sağlayacağı rapor edilmektedir [9].

GO üretim yöntemlerindeki en önemli dezavantajlar, toksik ve tehlikeli kimyasalların kullanılması ve oluşan ürünlerde bir takım zehirli gazların ortaya çıkmasıdır. Şu ana kadar yapılan çalışmalarda, çok tehlikeli olan $\mathrm{ClO}_{2}$ yerine $\mathrm{KMnO}_{4}$ gibi kuvvetli bir oksitleyici ajan ve dumanlı asit buharı oluşturan nitrik asit yerine sodyum nitrat kullanan ve reaksiyon süresini de kısaltan Hummers metodu [10] en avantajlı yöntem olmuştur. $\mathrm{Bu}$ yöntemde grafit; $\mathrm{KMnO}_{4}$, konsantre $\mathrm{H}_{2} \mathrm{SO}_{4}$ ve $\mathrm{NaNO}_{3}$ karışımı ile oksidasyon reaksiyonunaa sokulmuştur. Burada oluşan $\mathrm{Mn}_{2} \mathrm{O}_{7}$ gerçek oksidan tür olup aromatik yapılar üzerindeki doymamış alifatik çift bağları seçici olarak oksitlemektedir [11]. Bu yöntemin dezavantajları ise; $\mathrm{NO}_{2}$ ve $\mathrm{N}_{2} \mathrm{O}_{4}$ gibi toksik gazların oluşumu, sıcaklığın $95{ }^{\circ} \mathrm{C}$ 'nin üzerine çıkması durumunda $\mathrm{KMnO}_{4}$ 'nn patlama riski ve sulu çözeltiden kristal kafese hapsolan $\mathrm{Na}^{+}$ve $\mathrm{NO}_{3}{ }^{-}$iyonlarının uzaklaştırılma zorluğudur [12].

Bu yüzden yapılan sonraki çalışmalarda Hummers yöntemi modifiye edilip bu dezavantajları azaltma yolları araştırılmıştır. $\mathrm{Bu}$ çalışmalarda; reaksiyon şartları değiştirilmesi, $\mathrm{KMnO}_{4}$ yerine $\mathrm{K}_{2} \mathrm{FeO}_{4}$ kullanılması, $\mathrm{NaNO}_{3}$ yerine ise konsantre asit miktarının artırılması veya $\mathrm{H}_{2} \mathrm{SO}_{4}$ ile birlikte $\mathrm{H}_{3} \mathrm{PO}_{4}$ kullanılması gibi değişiklikler yapılmıştır [13].

Fourier dönşümlü kızıl ötesi spektroskopisi (FTIR) ile, katı ve sıv1 örneklerin kızıl ötesi aktif molekül özellikleri kullanılarak yapılarında bulunan bileşiklerdeki bağların durumu ve yerleri ve bileşik yapısının aromatik ya da alifatik olup olmadığ 1 belirlenir. FTIR spektroskopisi, 4000-400 cm${ }^{-1}$ frekans bölgesinde elektromanyetik radyasyonu absorplamak için kimyasal bağlarla birleştirilen kızıl ötesi aktif atomların temel özelliklerinden faydalanılır.

FTIR analizi ile farklı $\mathrm{NaNO}_{3}$ konsantrasyonlarıla elde edilen sentezler sonucunda, grafen okside dönüşümünün ve yapısal özelliklerinin değişiminin incelenmesi amaçlanmıştır.

\section{Materyal ve Metot}

\subsection{Kullanılan Kimyasallar ve Materyaller}

Çalışmada; merck-325 meş grafit tozu, merck-sodyum nitrat, merck -\%98'lik sülfürik asit, merck-potasyum permanganat, ultra deiyonize su, merck-\%30'luk hidrojen peroksit ve fluka-\%37'lik hidroklorik asit kimyasalları kullanılmıştır. Materyal olarak ise; 250 ml'lik cam reaktör, ultrasonik banyo $150 \mathrm{w}$ (çalışkan lab.), çeker ocak, 1sıtıcılı manyetik karıştırıcı (1ka yellowline msh basic), pH metre (mettler toledo), santifürüj cihazı, etüv, termometre kullanılmıștır.

\subsection{Deneysel Sistem}

Şekil 1'de GO sentezi için deneysel akış şeması verilmiştir. Burada oksidasyon reaksiyonu; $1 \mathrm{~g}$ grafit tozu, 0-1g aralı̆̆ında değişen $\mathrm{NaNO}_{3}$ ve $23 \mathrm{~mL} \mathrm{H}_{2} \mathrm{SO}_{4}$ 'in $250 \mathrm{~mL}$ 'lik cam reaktöre ilave edilmesiyle başlanmıştır. Karışım, $30 \mathrm{dk}$ homojen bir süspansiyonun elde edildiği 500 rpm'de karıştırılıp literatürdeki diğer modifiye Hummers yöntem- lerinden farklı olarak 40 dakika boyunca $-15{ }^{\circ} \mathrm{C}^{\prime} \mathrm{de}$ dondurucuda bekletilmiştir. Daha sonra numune buz banyosunda $0^{\circ} \mathrm{C}^{\prime}$ ye getirilmiş ve yaklaşı 1 saat boyunca kademeli olarak $3 \mathrm{~g} \mathrm{KMnO}_{4}$ ilave edilerek Eşitlik 1-2 oksidasyon reaksiyonları gerçekleştirilmesiyle koyu yeşil renkli grafit oksit oluşumu gözlenmiştir (bu aşamada sıcaklık $5^{\circ} \mathrm{C}$ 'yi geçmemelidir) [14].

$\mathrm{KMnO}_{4}+3 \mathrm{H}_{2} \mathrm{SO}_{4} \rightarrow K^{+}+\mathrm{MnO}_{3}^{+}+\mathrm{H}_{3} \mathrm{O}+3 \mathrm{HSO}_{4}^{-}$

$\mathrm{MnO}_{3}^{+}+\mathrm{MnO}_{4}^{-} \rightarrow \mathrm{Mn}_{2} \mathrm{O}_{7}$

Sicaklık $35 \quad{ }^{\circ} C^{\prime}$ ye ayarlanıp numune 2 saat boyunca karıştırıldıktan sonra (sıcaklık bu aşamada $50{ }^{\circ} \mathrm{C}^{\prime} \mathrm{yi}$ geçmemelidir) GO’ya dönüştürülmüştür. Açık kahverengiye dönen karışımın sıcaklığı $98{ }^{\circ} C^{\prime}$ 'ye yükseltilip kontrollü bir biçimde $46 \mathrm{~mL}$ ultra saf su ilave edilerek $15 \mathrm{dk}$ daha karıştırılıp rengin koyu kahveye dönüştüğü gözlenmiştir. Daha sonra, 140 $\mathrm{mL}$ ultra saf su ve $8 \mathrm{~mL} \mathrm{H}_{2} \mathrm{O}_{2}$ ilavesiyle renk sarıya dönmüş ve $\mathrm{KMnO}_{4}$ fazlası Eşitlik (3)'de gösterildiği gibi suda çözünen mangan sülfat tuzuna dönüştürülmüştür.

$2 \mathrm{KMnO}_{4}+3 \mathrm{H}_{2} \mathrm{SO}_{4}+3 \mathrm{H}_{2} \mathrm{O}_{2} \rightarrow 2 \mathrm{MnSO}_{4}+2 \mathrm{~K}_{2} \mathrm{SO}_{4}+8 \mathrm{H}_{2} \mathrm{O}+$

Son karışım 24 saat oda sıcaklığında bekletildikten sonra süzülüp ayrılan katı numune, bünyesindeki metal iyonlarını gidermek için \%10’luk $\mathrm{HCl}$ ile ve reaksiyona girmeyen asit fazlasını gidermek için saf su ile pH 7 olana kadar yıkanmıştır. Karışım $60^{\circ} \mathrm{C}$ 'deki etüvde 4 saat kurutulduktan sonra saf su ilave edilerek elde edilen grafen oksit süspansiyonu 2 saat sonikasyona (güç: $150 \mathrm{~W}$ ve frekans: $33 \mathrm{KHz}$ ) tabi tutulmuş ve $5 \mathrm{dk}$ boyunca 3000 dev.dk ${ }^{-1}$ hız ile santifürüj edilerek çözeltisinden ayrılmıştır. 986 
Son olarak, katı numune $60{ }^{\circ} \mathrm{C}$ 'deki etüvde 24 saat kurutularak GO sentezi gerçekleştirilmiştir.

Elde edilen numunelere, $\mathrm{NaNO}_{3}$ '1n artan konsantrasyonuna göre sırasıyla, GO-Na0 ve GO-Na0,50 kodları verilmiştir.

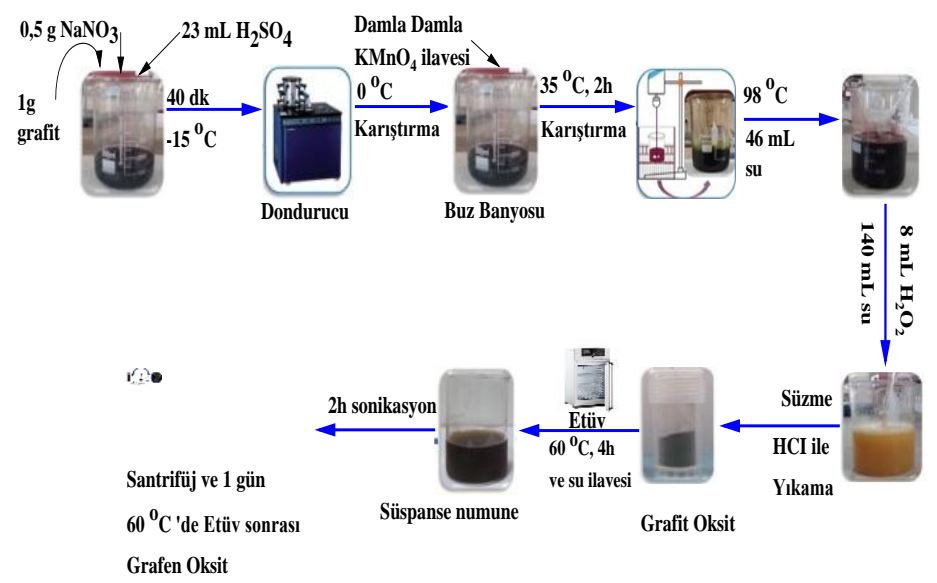

Şekil 1. Grafen Oksit Sentezi için Deneysel Akış Şeması

\subsection{Ray Difraksiyonu Analizi}

Grafit ve sentez numunelerinin FTIR görüntüleri, Bruker Verteks 70v model spektroskopisi ile 400-4000 $\mathrm{cm}^{-1}$ frekans bölgesinde tarama yapılarak oksijen içeren fonksiyonel grupların (epoksi, karboksil, hidroksil vs) belirlenmesi için elde edilmiştir.

\section{Araştırma Sonuçları ve Tartışma}

Çok sayıda fonksiyonel gruba sahip bir platform olan GO, çok zengin ve karmaşık spektrumlar sergiler. Şu ana kadarki çalışmalarda yapılan incelemelerde GO'nun FTIR spektrumları farklı yorumlandığı gözlenmiştir. Yapılan yayınların çoğunda, verilerin daha önce yanlış yorumlanan eserlere atıfta bulunulduğundan bu yanlış yorumlar yeniden üretilmektedir. Aşağıda, doğru yorumlanmış spektrumlar ve yapılan en tipik farklı yorumlar izah edilmiştir [15].

Tipik bir GO FTIR spektrumu (Şekil 2) keyfi olarak üç karakteristik bölgeye ayrılır. Bunlar; (i) 3600-2400 $\mathrm{cm}^{-1}$ bölgesinde yoğun ve çok geniş bir absorpsiyon bandı, (ii) spektrumun ortasında en çok tanınan iki absorpsiyon bandı 1723 $\mathrm{cm}^{-1}$ ve $1619 \mathrm{~cm}^{-1}$ ve (iii) parmak izi bölgesinde bir grup üst üste binen sinyallerdir.

3600-2400 $\mathrm{cm}^{-1}$ absorpsiyon bandı, O-H bağlarının gerilme modlarından kaynaklanmakta olup alkoller ve GO yapısına dahil edilen su molekülleri buna neden olur [15].

Spektrumun ortasındaki $1723 \mathrm{~cm}^{-1}$ ve $1619 \mathrm{~cm}^{-1}$ deki absorpsiyon bantları, GO-FTIR spektrumlarının imzası niteliğindedir. Bu iki bant, GO'larda görülmelidir.

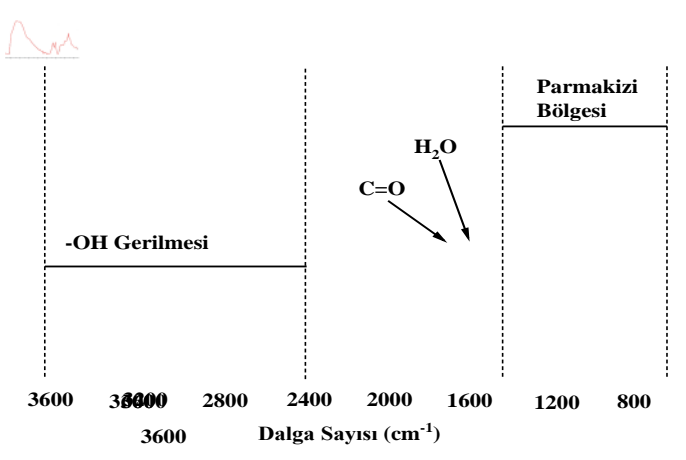

Şekil 2 Tipik bir GO numunesi Için FTIR spektrumu

Yapılan çalışmalarda ilk pikin konumu $1710-1726 \mathrm{~cm}^{-1}$ ve ikinci pikin konumu 1610-1624 $\mathrm{cm}^{-1}$ arasında değiştiği gözlenmiştir. Bu kaymaların, büyük olasılıkla GO örneklerinin doğasından çok kullanılan enstrüman ve yöntemle alakalı olduğu bildirilmiştir. $1723 \mathrm{~cm}^{-1}$ band1, açık bir şekilde karbonil $(\mathrm{C}=\mathrm{O})$ lerin gerilme modundan kaynak- landığ $\breve{1}_{\text {konusunda ortak }}$ bir fikir birliği vardır. $1619 \mathrm{~cm}^{-1}$ bandı, literatürde yaygın olarak farklı yorumlanan absorpsiyon bandıdır. Yakın tarihli GO ile ilgili literatürde, en yaygın yorum $\mathrm{C}=\mathrm{C}$ bağlarının gerilme modları olsa dahi farklı türlerle yorumlanan yayınlar da bulunmaktadır [15].

Parmak izi bölgesindeki bantların yorumlamaları, farklı fonksiyonel gruplardan çoklu bantların üst üste binmesi nedeniyle daha zordur. Yukarıda tartışılan iki bandın aksine, parmak izi bölgesindeki bantların bildirilen konumları ve yoğunlukları yöntemsel olarak değişmektedir [15-18]. Parmak izi bölgesindeki en yoğun bant, 1039-1060 $\mathrm{cm}^{-1}$ 'de rapor edilmiştir. Bu kaymanın sebebi GO örneklerindeki yapısal farktan kaynaklanır. Bu aralıkta oluşan bandı, epoksi halkalar şeklinde yorumlayan birçok çalışma olmasına rağmen epoksi halkalar $\sim 1220 \mathrm{~cm}^{-1}$ de absorplanırlar. Parmak izi bölgesinde bildirilen diğer güçlü absorpsiyon bantları 1368 ve $1420 \mathrm{~cm}^{-1}$ dir. Bu bantlar, sirasiyla alkol gruplarının bükülme modlarına [15,19] ve hidrojen bağlarında O-H'nin hidroksil, epoksi veya sülfat gruplarının hetero atomlarına olan deformasyon modlarına [18] atanmıştır. $\mathrm{Bu}$ bantlar- dan başka GO'nun FTIR spektrumunda yaklaş1k $2100 \mathrm{~cm}^{-1}$ ve $2340 \mathrm{~cm}^{-1}$ civarında da oluşan bantların sırasıyla karboksil grubuna ve karbondiksite atandıkları birçok çalışmada bulun- maktadır. Bununla birlikte, parmak izi bölgesinde açıklanan tüm bu atamaların spekülatif olduğu da bilinmelidir [15].

Grafitin FTIR spektrumunda ise, herhangi bir fonksiyonel grupla ilgili önemli pikler bulunmaz. Fakat absorbe edilen su moleküllerine atanabilen bantlar ortaya çıkabilir. Çalışmada kullanılan grafitin ve seçilen sentez numunelerinin FTIR spektrumları sırasıyla, Şekil 3-4'de verilmiştir. Şekillerden elde edilen dalga sayısı değerleri ve band atamaları Tablo 1'de sunulmuştur. 


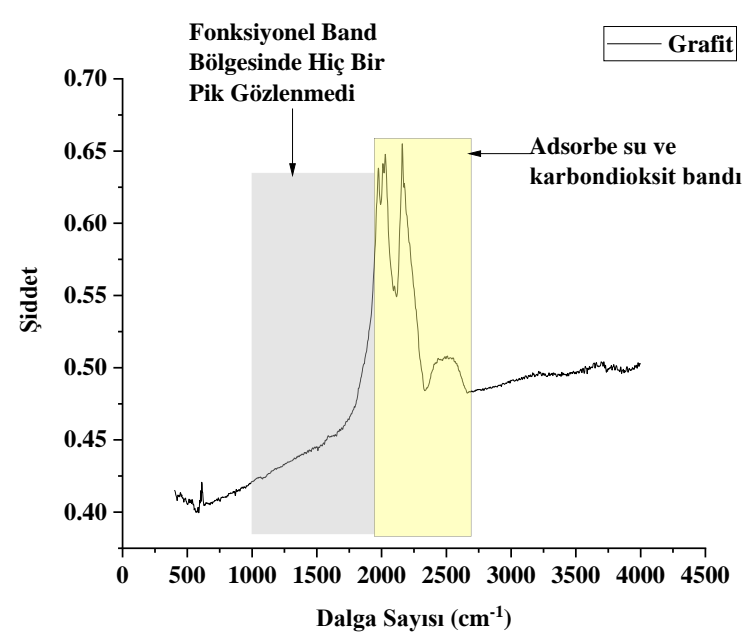

Şekil 3 Grafitin FTIR Spektrumu

Tablo 1 Seçilen GO Sentezlerinin FTIR Sonuçları

\begin{tabular}{|c|c|c|}
\hline \multicolumn{2}{|c|}{ Dalga Sayısı $\left(\mathrm{cm}^{-1}\right)$} & \multirow[t]{2}{*}{ Fonksiyonel Grup } \\
\hline GO-Na0 & $\begin{array}{l}\text { GO- } \\
\text { Na0,50 }\end{array}$ & \\
\hline 1033 & 1036 & C-O alkoksi gerilme titreşimi \\
\hline 1214 & 1212 & C-O-C epoksi gerilme titreşimi \\
\hline 1338 & 1338 & $\mathrm{C}-\mathrm{OH}$ bükülme titreşimi \\
\hline 1616 & 1612 & $\mathrm{C}=\mathrm{C} \mathrm{sp}{ }^{2}$ hibridize gerilme titreşimi \\
\hline 1716 & 1718 & $\mathrm{C}=\mathrm{O}$ karbonil gerilme titreşimi \\
\hline 2094 & 2092 & $\mathrm{O}-\mathrm{C}=\mathrm{O}$ karboksil gerilme titreşimi \\
\hline 2341 & 2341 & $\begin{array}{l}\text { Atmosferik } \mathrm{O}=\mathrm{C}=\mathrm{O} \text { gerilme } \\
\text { titreşimi }\end{array}$ \\
\hline $\begin{array}{l}3000- \\
3700\end{array}$ & $3000-3700$ & -OH gerilme titreşimi \\
\hline
\end{tabular}

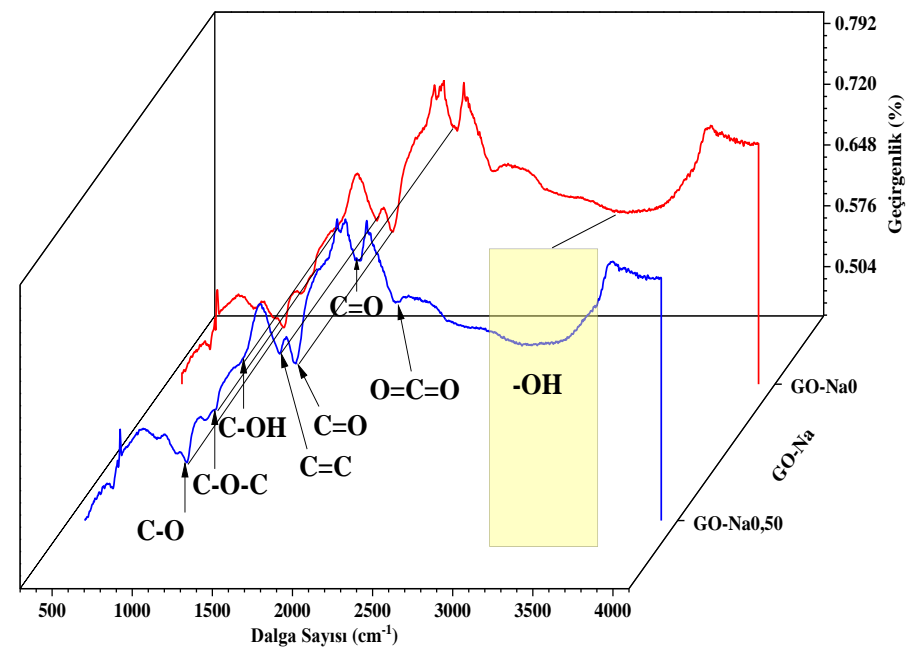

Şekil 4 GO-Na FTIR Spektrumlarl

\section{Sonuç}

Şekil 3-4 ve Tablo 1 incelenildiğinde aşağıdaki sonuçlar elde edilmiştir.
- Grafitin FTIR spektrumunda, herhangi bir fonksiyonel grupla ilgili anlamlı pikler gözlenmemiştir. Ancak adsorbe edilen su ve karbondioksitten dolay1 2100-2500 $\mathrm{cm}^{-1}$ bant aralığında pikler gözlenmiştir.

- Kimyasal oksidasyondan sonra FTIR spektrumlarında oksijen içeren fonksiyonel gruplara atfedilen yeni bantlar ortaya çıkmıştır.

- Alkoksi, epoksi ve fenolik karbon (C-O) grupları sirasıyla; 1034, 1213 ve $1338 \mathrm{~cm}^{-1}$ band aralığında ortaya çıkmıştır.

- GO-FTIR spektrumlarında mutlaka görülmesi gereken iki bant; $\mathrm{sp}^{2}$ hibridize karbon $(\mathrm{C}-\mathrm{C} / \mathrm{C}=\mathrm{C})$ atomlarının varlığına atfedilen $\sim 1615 \mathrm{~cm}^{-1}$ ve karbonil grubuna atfedilen $\sim 1717 \mathrm{~cm}^{-1}$ değerlerinde ortaya çıkmıştır.

- Karboksil grubunun titreşim modunun $2093 \mathrm{~cm}^{-1}$ bandında gerilmesiyle ortaya çıkmıştır.

- Sentez numunelerinde ayrica, atmosferik karbondioksitten dolayı $2341 \mathrm{~cm}^{-1}$ bandında ortaya çıkmıştır.

- Absorplanan su molekülleri, -OH gerilmesine katkıda bulunan $3000-3700 \mathrm{~cm}^{-1}$ gibi geniş bir band aralığında tepe şeklinde ortaya çıkmıştır. Bu, grafit ve su molekülleri arasında hidrojen bağlarının oluşmasına neden olup hidrofilik özellik göstermesine neden olmuştur.

$\mathrm{Bu}$ kısımda elde edilen sonuçlar, FTIR analizi ile elde edilen sonuçlarla karşılaştırıldığında uyum içerisinde olduğu gözlenmiştir. Bütün sonuçlar 1şığında, bu şartlarda elde edilen sentezlerin, farklı özelliklere sahip grafen oksit örnekleri oldukları ve literatür ile uyum içerisinde oldukları söylenebilir.

\section{Teşekkür}

$\mathrm{Bu}$ çalışma, Atatürk Üniversitesi BAPSİS Birimi tarafından Temel Araştırma Projesi olarak desteklenmiştir.

\section{Kaynakça}

[1] Moosa, A., and Abed, M. (2021). Graphene preparation and grapfite exfoliation. Turkish journal of Chemistry, 45(3),493-519.

[2] Dresselhaus, G., Dresselhaus, M. S., \& Saito, R. (1998). Physical properties of carbon nanotubes. World scientific.

[3] Chen, J., Yao, B., Li, C., \& Shi, G. (2013). An improved Hummers method for eco-friendly synthesis of graphene oxide. Carbon, 64, 225-229.

[4] Huang, X., Qi, X., Boey, F., \& Zhang, H. (2012). Graphenebased composites. Chemical Society Reviews, 41(2), 666686. 
[5] Tiyek, İ., Dönmez, U., Yıldırım, B., Alma, M. H., Ersoy, M. S., \& Karataş, Ş. (2016). Kimyasal yöntem ile indirgenmiş grafen oksit sentezi ve karakterizasyonu. Sakarya University Journal of Science, 20(2), 349-357.

[6] Paulchamy, B., Arthi, G., \& Lignesh, B. D. (2015). A simple approach to stepwise synthesis of graphene oxide nanomaterial. J Nanomed Nanotechnol, 6(1), 1.

[7] Sun, L., \& Fugetsu, B. (2013). Mass production of graphene oxide from expanded graphite. Materials Letters, 109, 207210.

[8] Brisebois, P. P., \& Siaj, M. (2020). Harvesting graphene oxide-years 1859 to 2019: a review of its structure, synthesis, properties and exfoliation. Journal of Materials Chemistry C, 8(5), 1517-1547.

[9] Shamaila, S., Sajjad, A. K. L., \& Iqbal, A. (2016). Modifications in development of graphene oxide synthetic routes. Chemical Engineering Journal, 294, 458-477.

[10] Hummers Jr, W. S., \& Offeman, R. E. (1958). Preparation of graphitic oxide. Journal of the american chemical society, 80(6), 1339-1339.

[11] Dreyer, D. R., Park, S., Bielawski, C. W., \& Ruoff, R. S. (2010). The chemistry of graphene oxide. Chemical society reviews, 39(1), 228-240.

[12] Lavin-Lopez, M. D. P., Romero, A., Garrido, J., SanchezSilva, L., \& Valverde, J. L. (2016). Influence of different improved hummers method modifications on the characteristics of graphite oxide in order to make a more easily scalable method. Industrial \& Engineering Chemistry Research, 55(50), 12836-12847.

[13] Marcano, D. C., Kosynkin, D. V., Berlin, J. M., Sinitskii, A., Sun, Z., Slesarev, A., ... \& Tour, J. M. (2010). Improved synthesis of graphene oxide. ACS nano, 4(8), 4806-4814.

[14] Peng, L., Xu, Z., Liu, Z., Wei, Y., Sun, H., Li, Z., ... \& Gao, C. (2015). An iron-based green approach to 1-h production of single-layer graphene oxide. Nature communications, 6(1), 1-9.

[15] Eigler, S., \& Dimiev, A. M. (2016). Characterization techniques. Graphene Oxide: Fundamentals and Applications. Chichester, UK: John Wiley and Sons.

[16] Pendolino, F., Parisini, E., \& Lo Russo, S. (2014). Timedependent structure and solubilization kinetics of graphene oxide in methanol and water dispersions. The Journal of Physical Chemistry C, 118(48), 28162-28169.

[17] Ambrosi, A., Chua, C. K., Bonanni, A., \& Pumera, M. (2012). Lithium aluminum hydride as reducing agent for chemically reduced graphene oxides. Chemistry of Materials, 24(12), 2292-2298.

[18] Seredych, M., \& Bandosz, T. J. (2010). Combined role of water and surface chemistry in reactive adsorption of ammonia on graphite oxides. Langmuir, 26(8), 5491-5498.

[19] Szabó, T., Berkesi, O., \& Dékány, I. (2005). DRIFT study of deuterium-exchanged graphite oxide. Carbon, 15(43), 3186-3189. 